\title{
EGU2020-20306
}

https://doi.org/10.5194/egusphere-egu2020-20306

EGU General Assembly 2020

(c) Author(s) 2021. This work is distributed under

the Creative Commons Attribution 4.0 License.

\section{City-scale groundwater flow and heat transport modeling in the Milan Metropolitan Area}

\author{
Alberto Previati ${ }^{1}$, Giovanni Battista Crosta ${ }^{1}$, and Jannis Epting ${ }^{2}$ \\ ${ }^{1}$ University of Milan - Bicocca, Department of Earth and Environmental Sciences, Milano, Italy \\ (a.previati1@campus.unimib.it) \\ ${ }^{2}$ University of Basel, Department of Environmental Sciences, Basel, Switzerland (jannis.epting@unibas.ch)
}

Aquifers beneath big cities are considered a very important resource from an energy and water supply point of view and are increasingly exploited by means of groundwater extraction wells as well as by shallow open- and closed-loop geothermal systems. Moreover, the shallow subsurface of densely populated cities is increasingly hosting underground infrastructures such as tunnels and building foundations. These activities lead to thermal pollution of the shallow urban underground. This phenomenon has already been documented (urban heat island effect) in many cities worldwide with higher ground/groundwater temperatures in the city centers with respect to surrounding rural areas. The local thermal impact of various underground activities has been studied with analytical and local-scale numerical modeling. However, the resulting groundwater thermal regime at the city-scale is yet mostly unexplored.

In this work the effects of anthropogenic heat sources and subsurface infrastructures in the Milan metropolitan area is presented. To this aim a groundwater head/temperature monitoring network was established in 2016. Groundwater temperatures in the city center are up to $3^{\circ} \mathrm{C}$ higher with respect to less urbanized areas. A correlation between the urban density and the groundwater thermal regime was observed. In order to evaluate the spatial variability of the groundwater temperatures, a detailed analysis based on a 3D FEM groundwater flow and heat transport numerical model was carried out by means of the commercial code FeFlow. First, the variability of hydraulic and thermal properties as from borehole logs was spatialized into the model by means of 3D geostatistical techniques to account for aquifer heterogeneities. Complex thermal boundary conditions were assigned to the model including the effects of different land cover/sealing materials, building foundations, tunnels, shallow geothermal wells and the canal network. The thermal transport model was calibrated against high-resolution time-lapse groundwater temperature profiles and continuous measurements at fixed depth.

The modeling of the current thermal regime of the shallow aquifers was essential to understand the hydrogeological and thermal processes that are relevant at the city scale. The numerical results are a valuable tool to assess the impact of specific heat sources as well as of surface/subsurface infrastructures on the overall thermal regime and to test the long-term thermal potential of ground/groundwater heat exchangers under possible urban development 
scenarios. Thereby, the proposed approach can support the sustainable development of subsurface infrastructures at the city-scale and the management and assessment of the thermal potential of low enthalpy geothermal resources. 